\title{
La biografía imaginaria de escritor como modalidad del ensayo: Rimbaud le fils de Pierre Michon
}

\author{
Carles BESA CAMPRUBí \\ Universitat Pompeu Fabra \\ carles.besa@upf.edu
}

Recibido: $29 / 10 / 2012$

Aceptado: 11/01/2013

\begin{abstract}
Resumen
A medio camino entre la ficción y la dicción, la biografía imaginaria de escritor es una forma específica del género de la biografía ficcional cuyas características enunciativas, semánticas y pragmáticas se entrecruzan, en mayor o menor medida, con las características propias del género del ensayo. Más allá de la recreación imaginaria de la existencia del escritor a partir de las posibilidades que ofrece la ficción, esta clase de textos tiene, asimismo, un propósito crítico y polémico, pues su objeto es también acceder a algún tipo de verdad nueva acerca de la literatura misma. Corrobora esta hipótesis el análisis de Rimbaud le fils, una obra que ocupa una posición central en la ruptura estética de finales del siglo XX, no sólo por su carácter renovador en relación con las convenciones de la biografía, sino también por su posicionamiento heterodoxo respecto de los sistemas explicativos del hecho literario.
\end{abstract}

Palabras clave: biografía ficcional, biografía imaginaria de escritor, ensayo, Pierre Michon, Rimbaud le fils.

\section{La biographie imaginaire d'écrivain comme modalité de l'essai : Rimbaud le fils de Pierre Michon}

\section{Résumé}

Entre fiction et diction, la biographie imaginaire d'écrivain est une forme spécifique du genre de la biographie fictionnelle dont les caractéristiques énonciatives, sémantiques et pragmatiques recoupent en grande partie les caractéristiques du genre de l'essai. Au-delà de la recréation imaginaire de l'existence de l'écrivain à partir des possibilités qu'offre la fiction, cette classe de textes relève également d'une visée critique voire polémique, son objet étant en grande mesure une pensée originale sur la littérature elle-même. Cette hypothèse est vérifiée par l'analyse de Rimbaud le fils, qui occupe une position charnière dans la rupture esthétique des dernières décennies $\mathrm{du} \mathrm{XX}^{\mathrm{e}}$ siècle, non seulement par son caractère rénovateur vis-à-vis des conventions de la biographie, mais aussi par son positionnement hétérodoxe au regard des systèmes explicatifs du fait littéraire.

Mots clés: biographie fictionnelle, biographie imaginaire d'écrivain, essai, Pierre Michon, Rimbaud le fils. 


\title{
The Writer's imaginary biography as a modality of the essay: Rimbaud le fils by Pierre Michon
}

\begin{abstract}
Situated halfway between fiction and diction, the writer's imaginary biography is a particular form of the fictional biography genre, whose enunciative, semantic and pragmatic characteristics are interweaved, to a varying degree, with those of the essay. In addition to the imaginary recreation of a writer's life offered by fiction, this type of text has also a critical and polemical purpose, as it intends to deliver an original and revitalizing view of literature as such. This hypothesis is verified in the analysis of Rimbaud le fils, a work that occupies a prominent position in the aesthetic break-up of the last decades of the $20^{\text {th }}$ century, due not only to its reinvigorating approach to biography conventions, but also to its heterodox stance regarding the current explanatory systems of the literary edifice.
\end{abstract}

Keywords: Fictional biography, writer's imaginary biography, essay, Pierre Michon, Rimbaud le fils.

\section{Referencia normalizada}

Besa Camprubí, C. (2013). "La biografía imaginaria de escritor como modalidad del ensayo: Rimbaud le fils de Pierre Michon”. Thélème, Vol. 28, 45-60.

\section{Sobre la hibridación del género ensayo}

En este artículo voy a tratar de una clase particular de obras que la teoría y la crítica literarias ubican dentro de lo que se ha dado en llamar "biografía fíccional". Con esta etiqueta se suele designar un número muy variado de producciones, que tienen en común su rechazo del relato biográfico tradicional, que sufre una profunda crisis a partir de los años 1980, de la misma forma a como un siglo antes había entrado en la "era de la sospecha" la novela realista ${ }^{1}$. La clase de textos que me interesa aquí es la constituida por los relatos biográficos imaginarios de autores de ficción (es decir, no periodistas, historiadores o académicos, pongamos por caso) sobre otros escritores. Y la hipótesis que quiero defender es que esta clase de textos presenta a menudo características enunciativas, semánticas y pragmáticas que coinciden o se entrecruzan con las características propias del género del ensayo. Ello es así por cuanto el objeto principal de la biografía imaginaria de escritor es precisamente el de explorar las relaciones entre creación y creador con el fin de acceder a algún tipo de verdad sobre la literatura. En la segunda parte del artículo intentaré validar mi hipótesis por medio del análisis de Rimbaud le fils de Pierre Michon, una obra que

${ }^{1}$ Sobre las líneas maestras, evolución y paradojas de la literatura biográfica de los últimos años en la narrativa francesa, remito a los estudios de Dominique Viart (2001a y 2002). 
ocupa una posición central en la ruptura estética de finales del siglo XX no sólo por su carácter renovador en relación con las formas y convenciones de la biografía - según la perspectiva crítica dominante-, sino también por su posicionamiento heterodoxo en relación con los sistemas explicativos de lo literario - lo que convierte a Rimbaud le fils en un ensayo, una cuestión que, a mi entender, ha sido poco abordada.

Por pertenecer al género de la biografía ficcional, la biografía imaginaria de escritor tiene un estatuto paradójico, pues su rasgo característico es el de atribuir a un personaje histórico real — por tanto, de existencia probada - cualidades, aventuras y episodios ficticios en mayor o menor grado. Se trata, pues, de un caso evidente de amalgama o de mestizaje de los dos regímenes de literariedad que definió Gérard Genette en Fiction et diction, y sobre cuya coexistencia el propio Genette expresa sus reservas unos años después (Genette, 2003). Así, en los géneros "puros" (pongamos por caso una novela, una pieza de teatro, una biografía histórica o unas memorias), ficción y dicción serían "incompatibles", o tendrían un grado diferente de perceptibilidad o de disfrute (para ilustrar esta incompatibilidad, Genette recuerda la anécdota relativa al presidente Ford, quien era incapaz de leer el periódico y mascar chicle al mismo tiempo): en una novela o una pieza de teatro la relación de ficcionalidad es superior a la relación de diccionalidad, puesto que la atención por la intriga (por la fábula, por el "qué"), supuestamente creada ex nihilo o con una referencialidad puramente interna al texto, atenúa en parte la atención por la forma; inversamente, la literariedad condicional de una biografía (no ficcional) o unas memorias - que parten de una materia previa ya dada, conocida, y en cierta modo verificable- explica que estas obras susciten más que las obras plenamente ficcionales una apreciación estética (la atención por el "cómo"). En cambio, una biografía ficcional puede ser constitutivamente (objetivamente) reconocida como obra de ficción y también condicionalmente (subjetivamente) apreciada como obra de dicción, es decir, por su valor formal. Por consiguiente, esta compatibilidad de los dos criterios de literariedad se daría sobre todo en las obras que pertenecen a un género mixto, mezcla de realidad y de ficción, como la novela histórica, la novela autobiográfica o la biografía ficcional. En estos géneros, sostiene Genette, la percepción de una literariedad-por-ficción no elimina o excluye el sentimiento de literariedad-por-dicción, y viceversa.

Como se deduce, este carácter mixto de la biografía ficcional es un argumento a favor de una aproximación al género no purista o esencialista - siguiendo, pues, el modelo de un sistema analógico (Ryan, 2001) - , y por tanto preocupada por los fenómenos de movilidad, permeabilidad e interrelación de los géneros. En este sentido, podríamos decir que la biografía ficcional es a la biografía histórica lo que la autoficción es a la autobiografía. Esta analogía proportionalis sitúa la biografía ficcional en una cartografía de los géneros que no sólo elimina el carácter rígido y 
taxonómico de las clasificaciones genéricas tradicionales propias de sistemas discretos o digitales, sino que también permite, en un nivel mucho más concreto, dar cuenta del auge actual del género, cuya institucionalización en el campo literario contemporáneo es ya un hecho consolidado ${ }^{2}$. Así, podría decirse que, de la misma forma que la autoficción ha acabado cuestionando a la autobiografía como consecuencia del derrumbe de la noción misma de identidad, la biografía ficcional se está erigiendo en una respuesta crítica a la biografía factual o referencial como resultado del descrédito de las pretensiones de verdad y de facticidad sobre las que se sustentaba la vieja biografía.

Otra propuesta de definición transgenérica de la biografía ficcional contemporánea habla de ella en tanto que "ensayo-ficción" (Viart, 2001b) o "ficción crítica" (Viart, 2003). Partiendo de los principios de pluralidad y contaminación genérica de Derrida $^{3}$, Viart intenta acotar la biografía ficcional sirviéndose de la figura geométrica del pentaedro, cada una de cuyas caras sería ocupada por un género diferente, a saber: la biografía, la autobiografía, la ficción, la poesía y el ensayo. La idea de Viart es que cada biografía ficcional ocupa en este espacio un punto móvil según las formas de escritura que prioriza. Me permitiré reformular este modelo sustituyendo ficción y autobiografia por, respectivamente, novela y autoficción, pues parto de la base de que la ficción no es propiamente ningún género, y de que la cara "autobiografía" de cualquier biografía ficcional adopta, en mayor o menor grado, la modalidad de la autoficción.

La cara del pentaedro de Viart que a mi modo de ver merece más interés para la delimitación de la biografía imaginaria de escritor es la del ensayo, en gran parte ignorada o poco atendida por la bibliografía crítica, que se ha dedicado sobre todo a estudiar el carácter ficticio de esta clase de textos, y se ha mostrado, pues, poco sensible a la invitación del propio Viart, patente en la acuñación misma del término "ensayo-ficción". Es obvio que las caras "biografia" y "ficción" (o "novela" según mi reformulación) ya están ocupadas de facto y por principio por toda obra que merezca la etiqueta de biografía ficcional; en cuanto a la poesía, me parece que es

\footnotetext{
${ }^{2}$ Como recuerda Alexandre Gefen (2012), el momento fundador de la biografía ficcional coincide con la publicación en 1991 del número 224 de la Revue des sciences humaines, titulado "Le Biographique", en el que Alain Buisine propone el neologismo de "bioficción". Un año después, el género será objeto de un estudio de Daniel Oster en el suplemento Universalia de la Encyclopaedia Universalis, aparecerá en las historias de la literatura (Viart, 1999: 136), e incluso en los manuales escolares, con motivo de la inclusión del tema "Le biographique" en el programa de la prueba previa de francés de la selectividad. En cuanto, más especifícamente, a la modalidad de la biografía imaginaria de escritor, el corpus que en 2007 habían constituido Robert Dion y Frances Fortier contaba con más de 200 títulos de una decena de literaturas de tradiciones diferentes (Dion, 2007: 280). Dion y Fortier están llevando a cabo un proyecto de investigación sobre "Biographie fictive d'écrivain et effets de transposition".

3 "Et s'il y était impossible, de ne pas mêler les genres ? Et s'il y avait, logée au coeur de la loi même, une loi d'impureté ou un principe de contamination ? [...] Tout texte participe d'un ou de plusieurs genres. Il y a toujours du genre et des genres mais cette participation n'est jamais une appartenance" (Derrida, 1980: 178 y 185).
} 
un género muy marginal o residual, $\mathrm{y}$, en todo caso, siempre muy subordinado a las formas del relato propias de la biografía (por poética que ésta $\operatorname{sea}^{4}$ ); y por lo que respecta, finalmente, a la autoficción, rara vez la biografía de un escritor sobre otro escritor deja de ser un texto proyectivo en el que el autor se busca o se reconoce a sí mismo a través de su modelo (Boyer-Weinmann, 2005: 199). En este sentido, pues, una buena parte de las aproximaciones a la biografía ficcional corren el peligro de caer en formulaciones redundantes cuando no circulares ${ }^{5}$. Mi tesis es que la biografía imaginaria de escritor es muy a menudo un ensayo camuflado, un ensayo que no se atreve a decirse y menos aún a exhibirse como tal, y que utiliza los moldes genéricos de la biografía, la novela y la autoficción como tarjetas de presentación, como puentes intercesores, si se quiere, en un intento de autolegitimación por medio de estos géneros "canónicos" (y los dos últimos, además, constitutivamente literarios), lo que revela la precaria situación del ensayo en el mapa de los géneros. El ensayo podría de alguna forma considerarse como un género "relativo", la "sombra" de las otras especies de la prosa, como consecuencia del debilitamiento de la estructura de los géneros reconocidos. Es lo que sostiene Marielle Macé (2005), al apuntar que el ensayo puede ser definido no sólo por su relación con otros géneros (lo cual es obvio para cualquier género, aunque sin duda en menor medida), sino sobre todo por el desplazamiento al que somete otros géneros. La similitud entre varios ensayos diferentes no se explicaría tanto por el hecho de que compartan enunciados comparables cuanto por el hecho de consistir en una desviación o un juego con los discursos del saber o las formas de literariedad coetáneas ${ }^{6}$. En conse-

\footnotetext{
${ }^{4}$ Pienso, por ejemplo, en la obra sobre Trakl Blesse, ronce noir, de Claude Louis-Combet, paradigmática de las biografías imaginarias de escritor que ocupan la cara poética del pentaedro, y en las que el isomorfismo entre el sujeto biógrafo y el sujeto biografiado los hace apenas indiscernibles. Como apunta Francis Vanoye, en ese tipo de biografías la (con)fusión del autor con la obra o con el biografiado traduce la imposibilidad de una "relación de objeto"; el autor permanece "dans l'indifférenciation, dans ce moment où le vif ne se distingue pas du mort, où la complaisance à cette indifférenciation se lit dans la pesanteur de l'écriture" (Vanoye, 1989: 204).

${ }^{5}$ Esta tendencia es en parte expresión del credo panficcionalista, vinculado a Hayden White, quien opina que todo discurso narrativo, incluidos los discursos histórico y teórico, es una forma de ficción: "Readers of histories and novels can hardly fail to be struck by the similarities. There are many histories that could pass for novels, and many novels that could pass for histories, considered in purely formal (or I should say formalist) terms. Viewed simply as verbal artifacts histories and novels are indistinguishable from one another" (White, 1978: 121-122). Esta posición se basa en una interpretación filosófica muy restrictiva de la lingüística saussureana que niega al lenguaje la posibilidad de referirse a la realidad extralingüística.

${ }^{6}$ En el mismo sentido que Macé, Irène Langlet (1995: 95-173) había mostrado que los teóricos del ensayo han intentado dar cuenta de las paradojas principales del género — su rechazo a pertenecer a ninguna categoría dada y su relación con los demás géneros - por medio de las nociones de "mixto", "entre-deux" y "en-deçà". Según la noción de mixto, el ensayo utiliza todas las formas para combinarlas armónicamente en un mestizaje propio; las teorías del "entre-deux" sitúan el ensayo en la intersección de todos los otros géneros (el ensayo no sería un género mestizo, sino un género apátrida); finalmente, las teorías del "en-deçà" consideran este "otro lugar" del ensayo como un "fuera" de los
} 
cuencia, puede ser un ensayo, por ejemplo, un diario que pierde su composición cronológica, una carta sin destinatario, un tratado que atenúa las formas de su argumentación... Y por qué no, yendo un poco más lejos en la desviación, una biografía que mina desde dentro el viejo género de la biografía y sus propósitos histórico-críticos en relación con lo literario cuando esta biografía tiene por objeto un escritor. Máxime un escritor como Rimbaud, podríamos añadir, por simbolizar un cierto pensamiento límite sobre el hecho literario (por la brevedad de su obra, su súbito abandono y su ilegibilidad), y que precisamente por ello se habría de convertir en un interlocutor permanente para todo escritor en ciernes ${ }^{7}$.

Antes de abordar el estudio de Rimbaud le fils se impone una precisión sobre el significado mismo del término "ensayo" porque, como subraya Marc Angenot (1982: 47), el uso moderno del vocablo es un caso ejemplar de homonimia, por cuanto designa dos tipos discursivos no sólo diferentes, sino en muchos puntos opuestos (al menos aparentemente): en efecto, un ensayo puede ser un producto sabio y erudito (como las obras que proponen las colecciones universitarias o científicas), o bien, al contrario, una obra más libre y personal, poco comprometida desde el punto de vista de la producción del saber. El primer tipo de ensayo es el ensayo cognitivo o ensayo-diagnóstico, y lo caracteriza una escritura "monológica", científica y didáctica, con el desleimiento del sujeto de la enunciación; el segundo es el ensayo-meditación —o ensayo-debate según la reformulación de Pierre Glaudes y Jean-François Louette (1999: 35), quienes insisten en el carácter crítico y polémico de este segundo tipo-, caracterizado por un pensamiento errático, la presencia dramatizada del sujeto de la enunciación y, en general, una escritura aforística. En el campo literario, el tipo de ensayo más valorado es, por supuesto, el segundo, en parte porque es el que permite recurrir a Montaigne como "autoridad", y porque es el que actualiza el nombre del género gracias a su carácter más experimental.

A continuación voy a mostrar que Rimbaud le fils, sin que se pueda negar su adscripción al género de la biografía ficcional, es una obra que puede ser leída también (o sobre todo) como un ensayo literario, y en los dos sentidos del término "literario": en su sentido modal, lo que acerca Rimbaud le fils al ensayo-meditación o ensayo-debate, y en su sentido temático - ya he sugerido que la obra plantea, aunque indirectamente, algunas "ideas fuertes" sobre la literatura-, por el que se aproxima al ensayo cognitivo (aunque sin duda en menor grado). Esta permeabilidad entre uno y otro tipo de ensayo revela el carácter problemático de la frontera entre ambos; diría incluso que una de las tendencias actuales del género (al menos en la literatura francesa) es un fenómeno de transvase o de desplazamiento por el

géneros (el ensayo es considerado como un antigénero, un no-género o un género anterior a los géneros).

${ }^{7}$ El propio Michon afirma, en una entrevista con Pierre-Marc de Biasi, que Rimbaud no puede no formar parte de la "bibliothèque neuronale" de todo aspirante a ingresar en el espacio literario (Michon, 2002: 101). 
que el ensayo-meditación está asumiento valores y funciones en principio propios del ensayo científico.

\section{Rimbaud le fils como ensayo-ficción}

En la medida en que la genericidad de una obra (máxime de una obra que oscila entre ficción y dicción) depende de su ficcionalidad, y en que los primeros signos de ficcionalidad (o de no ficcionalidad) se encuentran en el paratexto, lo primero que debemos hacer si queremos examinar Rimbaud le fils desde la poética de los géneros es analizar las unidades del paratexto más activas, es decir, más susceptibles de establecer un protocolo de orientación genérica (pero sin olvidar que este protocolo puede ser insuficiente o imperfecto, como veremos más adelante). A mi modo de ver, estas unidades del paratexto que merecen mayor atención son el autor, el título y la colección, y el pacto genérico que establecen dichas unidades fluctúa entre la biografía y la autoficción. En cuanto a la primera unidad, en el momento de publicar Rimbaud le fils Michon es conocido por ser autor de "vidas" (y, por tanto, se ha posicionado ya como reintérprete de un género antiguo y de dilatada tradición del que se inspira en menor o mayor medida la moderna biografía), sean éstas humildes (Vies minuscules, Vie de Joseph Roulin, cartero y modelo de Van Gogh) o bien nobles (Maîtres et serviteurs, dedicada a Goya, Watteau y Piero della Francesca). Con Rimbaud le fils, sin embargo, el género de la vida se desplaza ligeramente, por cuanto el modelo es ahora un escritor y no un ser anónimo o un artista, lo que favorece la proximidad con el propio autor $\mathrm{y}$, por tanto, fomenta la dimensión autoficcional de la obra ${ }^{8}$. Por su parte, la aposición "le fils" del título parece aportar una restricción temática y cronológica al relato biográfico, en clara sintonía con las manifestaciones contemporáneas del género, que ha abandonado sus viejas pretensiones de exhaustividad: Rimbaud como hijo (y no como eterno adolescente según la mitología más común) evoca en el lector la telaraña edípica en la que estuvo enredado el poeta, hijo de un padre ausente (como el propio Michon) y de una

\footnotetext{
${ }^{8}$ El epitexto paratextual confirma esta impresión. Entrevistado por Thierry Bayle, Michon declara, efectivamente, que "il y a dans cette figure [Rimbaud] une espèce de fatalité qui fait que quiconque écrit sur lui parle en fait de lui-même. Le jeune Arthur déclenche systématiquement ce tourniquet identificatoire [...]. Alors oui, quiconque parle de Rimbaud est un usurpateur, puisqu'il se met à sa place, puisqu'écrire sur Rimbaud c'est vouloir en douce occuper le trône de la «littérature en personne ». Mais —et si c'était cette volonté d'usurpation qui faisait les grands textes ?" (Michon, 1997: 102). Otros efectos especulares en el mismo sentido son de carácter intertextual, y por lo tanto mucho más indirectos. Así, en "Vie de la petite morte", el último de los relatos de Vies minuscules, Michon evoca la figura de su hermana Madeleine - "la petite morte, derrière les rosiers" (Michon, 1984: 246) - , en alusión al poema "Enfance" de Rimbaud, en el que el poeta utiliza los mismos términos para referirse, según algunos críticos, a su hermana Vitalie, también desaparecida ("C'est elle, la petite morte, derrière les rosiers" es el íncipit del segundo texto de "Enfance").
} 
madre castradora. El elemento paratextual más significativo es, no obstante, la colección. Rimbaud le fils se publicó en la colección de Gallimard "L'un et l'autre", creada en 1989 por Jean-Bertrand Pontalis (fundador de la Nouvelle Revue de psychanalyse), en recuerdo de la sección "Reconnaissance" de la NRF. La solapa de todas las obras de la colección incorpora un texto programático del propio Pontalis, quien declara que se propone publicar:

Des vies, mais telles que la mémoire les invente, que notre imagination les recrée, qu'une passion les anime. Des récits sujectifs, à mille lieues de la biographie traditionnelle. L'un et l'autre : l'auteur et son héros secret, le peintre et son modèle. Entre eux, un lien intime et fort. Entre le portrait d'un autre et l'autoportrait, où placer la frontière ?

El vínculo entre biografía y autoficción, los dos protocolos estipulados por separado por el nombre del autor y el título, se establece aquí sin ambages, como consecuencia directa de un desplazamiento natural de las fronteras genéricas. La biografía aparece así como un taller privilegiado de la fusión genérica, puesto que se trata de recurrir a ella no sólo para traspasar la barrera que separaría el relato factual del relato ficcional (barrera cuya porosidad habían puesto ya de manifiesto las obras anteriores de Michon), sino también la que distingue el retrato del autoretrato o autoficción. La biografía es entendida, pues, a la vez como una forma legítima de ficcionalización - en base al precepto tácito según el cual el sujeto, desde sus orígenes, "serait pris dans une ligne de fiction" (Lacan, 1966: 94) - y como escritura de sí mismo ("l'un e(s)t l'autre"), al precio de una ruptura con el fundamento mismo del género biográfico: la separación nítida entre el biógrafo y el biografiado (paradójicamente, lo que es inventado en relación con este último podría corresponder a la realidad del primero).

Sin embargo, como es bien sabido, el pacto propuesto por el paratexto no es siempre un criterio suficiente en relación con la genericidad del texto. La historia de la literatura está colmada de obras cuyo texto completa, corrige o incluso se opone a las "instrucciones" de su paratexto, lo que demuestra que la literariedad y la genericidad de una obra no dependen tanto de la intención declarada del autor (y complementariamente, de la del editor) como de la atención del lector, que puede tomar un rumbo divergente respecto de la dirección propuesta inicialmente. Traspasado el umbral del paratexto, Rimbaud le fils se revela menos como una biografia ficcional en la que se proyecta y se refleja el propio autor que como un ensayo crítico sobre el hecho literario. Las expectativas suscitadas por el paratexto únicamente se cumplen, y sólo en parte, en el íncipit y el éxplicit, "lugares" con los que el paratexto mantiene una especie de solidaridad "estratégica" (Biasi, 1990) y que parecen repartirse muy equitativamente los términos del contrato générico. Así, si el íncipit penetra en la novela familiar de Rimbaud (rubricando el pacto biográfico), el éxplicit evoca la novela familiar de Michon (suscribiendo el contrato autoficcional):

On dit que Vitalie Rimbaud, née Cuif, fille de la campagne et femme mauvaise, donna le jour à Arthur Rimbaud. On ne sait pas si d'abord elle maudit et souffrit ensuite, ou si elle maudit d'avoir à souffrir et dans cette malédiction persista [...]. Mais on sait que le mari de cette femme qui était le père de ce fils devint tout vif un fantôme, dans le purgatoire de garnisons lointaines où il ne fut 
qu'un nom, quand le fils avait six ans. [...] On dit que cet enfant, avec d'un côté de son pupitre ce fantôme et de l'autre cette créature d'imprécation et de désastre, fut idéalement scolaire et eut pour le jeu ancien des vers une vive attirance: peut-être que dans le vieux tempo sommaire à douze pieds il entendait le clairon fantôme de garnisons lointaines, et les patenôtres aussi de la créature de désastre (Michon, 1991: 13-14).

Les étoiles dansent à travers les feuillages sombres. La maison est plus noire que la nuit. Ah c'est peut-être de t'avoir enfin rejointe et te tenir embrassée, mère qui ne me lis pas, qui dors à poings fermés dans le puits de ta chambre, mère, pour qui j'invente cette langue de bois au plus près de ton deuil ineffable, de ta clôture sans issue. C'est que j'enfle ma voix pour te parler de très loin, père qui ne me parleras jamais (Michon, 1991: 109-110) ${ }^{9}$.

Pero pronto los padrenuestros de la madre y el eco imaginario de la corneta del padre de Rimbaud se convierten, como por incorporación sustitutiva, en los versos del poeta, de los que aquellos rezos y aquella música habrían sido el "pre-poema" (Ghitti, 2004: 251). Madre y padre desaparecen de la escena (el narrador insiste en que no poseemos ninguna fotografía suya, detalle importante en una obra en la que la fotografía funciona como trampolín narrativo e interpretativo) al ser desbancados por "l'autre parentèle" (Michon, 1991: 19), la parentela simbólica conformada por los grandes autores leídos por el niño ${ }^{10}$. El tema de la filiación apuntado por el título salta pues, súbitamente, de la esfera biológica a la esfera literaria, y la cuestión no será ya la relación de amor-odio entre madre e hijo y el peso que sobre éste tiene la sombra del Capitán, sino, entre otras, cómo posicionarse como escritor en la cadena de la historia de la literatura. Análogamente, el arranque autoficcional del éxplicit es desactivado en beneficio de una serie de interrogantes de factura blanchotiana en respuesta a las imposturas de la renuncia a la literatura: "Qu'est-ce qui relance sans fin la littérature ? Qu'est-ce qui fait écrire les hommes ? Les autres hommes, leur mère, les étoiles, ou les vieilles choses énormes, Dieu, la langue ?" (Michon, 1991: $10)$.

A partir del segundo capítulo, Rimbaud le fils se desmarca del relato biográfico, del que sólo conserva el esqueleto (una cierta progresión, más lógica que cronológica, distribuida en seis grandes escenas o cuadros). El narrador renuncia a trazar un

\footnotetext{
${ }^{9}$ Las menciones ambientales que preceden al discurso directo (“Ah c'est peut-être...”) recuperan el marco espacio-temporal en el que el narrador ha imaginado a Rimbaud en la página anterior, al inicio del párrafo ("Je peux l'imaginer sortant la nuit dans la cour de Roche. [...] C'est juillet et les grandes étoiles. [...] On ne voit pas Rimbaud, qui est là [...] dans l'ombre fraîche de la nuit", Michon, 1991: 108; las cursivas son mías), por lo que en las últimas líneas del éxplicit se puede observar, de hecho, un cruce o una confluencia enunciativa entre la voz del narrador y la voz de Rimbaud. Como observa Jean-Pierre Richard, en Rimbaud le fils, gracias a un sabio juego con los pronombres personales, no escuchamos en realidad a Rimbaud o a Michon, sino "uno y otro" a la vez (Richard, 1993: 140).

${ }^{10}$ También en Vies minuscules Michon posiciona a los autores como padres (por medio de una relación de homofonía entre "pairs" y "pères"): de su estancia en el internado dice el narrador que "c'était une pleine durée de sept ans au cours desquels le latin deviendrait mon bien [...], les auteurs mes pairs" (Michon, 1986: 93).
} 
"perfil singular" para pasar a esbozar una historia colectiva, la "biografía" de las lecturas que de la obra de Rimbaud vienen produciéndose desde hace más de un siglo, empezando por las de sus contemporáneos y acabando con las más recientes. El gran acierto de Michon consiste en la mirada profundamente irrespetuosa que proyecta no sólo sobre un objeto crítico (las interpretaciones de la obra de Rimbaud), sino también sobre el trabajo crítico mismo que canaliza y sirve de soporte a esta interrogación (el relato biográfico, que sólo subsiste como sombra de sí mismo, bajo la forma de un recorrido cultural), caricaturizando a un tiempo el tema y el método, es decir, el género de la crítica literaria y el género de la biografía, los dos discursos canónicos sobre un escritor. Los textos críticos que cita o a los que alude Rimbaud le fils son designados indiscriminadamente con el término burlón de "Vulgate" (Michon, 1991: 56, 59, 72, 73, 76 y 105), con todas las connotaciones que legitima este vocablo religioso en un contexto sistemáticamente desmitificador. Estos textos críticos son objeto de una evaluación explícita en el libro, y la primera de estas evaluaciones consiste en despojarlos de su naturaleza de críticos, reconociendo que no son, justamente, más que ficciones, tan fútiles como lo han llegado a ser para la modernidad los debates teológicos de la Edad Media: "Tous ces livres écrits sur Rimbaud, ce livre unique en somme tant ils sont le même, interchangeables quoique burlesquement affrontés comme au Moyen Âge les successives interprétations du filioque" (Michon, 1991: 53). Michon llega incluso a caricaturizar la figura del crítico asimilándolo a Pierrot — llamado anteriormente Gilles-, el necio idiota inmortalizado por Watteau, y con cuya impotencia y melancolía se identifica el propio Pierre Michon (se notará el coqueteo onomástico Pierrot-Pierre):

tous ces livres sont sortis de la main du Gilles. Le Gilles est mieux documenté que Banville ; un siècle de travaux l'informe; il en sait bien plus long sur la vie de Rimbaud que Rimbaud n'en sut jamais, on l'a dit avec raison ; il est plus moderne que Banville, avec plus de résolution moderne ; enfariné, moderne [...] Gilles regarde passer dans le vide l'œuvre et la vie d'un autre. Il appelle cela Arthur Rimbaud. Il l'invente: c'est la feerie que lui-même n'est pas. Hélas, Rimbaud a le don d'enfariner ceux qui l'approchent : et ce disant mes mains pendent, je m'enrhume ; si je bats mes basques il en sort de la farine (Michon, 1991: 54-55).

Lo mismo puede decirse de las interpretaciones sobre los textos en que se supone que Rimbaud defiende el surgimiento de una nueva razón poética, como la famosa "Lettre du Voyant" enviada a Paul Demeny, y que Michon califica también de mito, un "avatar de la vieille justification idéaliste, volontariste, missionnaire, magicienne, du poète — l'épate, le rideau de fumée pro domo" (Michon, 1991: 61), pero que para Rimbaud era ya una antigualla poética "dans l'instant même qu'il mit sa lettre à la boîte" o, más aún, "dans l'instant qu'il la signait" (Michon, 1991: 62). O como la vulgata del alejandrino, supuestamente destruido por Rimbaud en 1870, algo que Michon considera una hipótesis "guère moins sotte que celle de la voyance [...]. Une Vulgate absolument moderne" (Michon, 1991: 76). La modernidad simbolizada por Rimbaud en la liturgia crítica, resultado del propio mandato del poeta de ser "absolument moderne", es algo que el mismo Rimbaud no habría reconocido. Michon socava así los fundamentos de la vulgata crítica, calificándola de leyenda 
(no en vano, la "Légende dorée" es mencionada en la p. 63), o, peor aún, relegándola al submundo del rumor (el texto está plagado de modalizaciones de una enunciación real pero contestable, del tipo "On dit que"), sugiriendo que hay una subyacente discontinuidad entre los que suscriben la vulgata y la figura a la que pretenden celebrar.

La apuesta de Michon de utilizar los dispositivos ficcionales no tanto en relación con el propio artista (como hacen muchas biografías imaginarias de escritores, sobre todo las biografías noveladas), sino sobre todo en relación con sus comentadores se materializa en el uso perverso que hace el autor de los documentos bibliográficos, entre los que destaca el Album Rimbaud de la Pléiade (Matarasso \& Petitfils, 1967) ${ }^{11}$. Este es, sin duda, el principal hipotexto declarado de Rimbaud le fils, el relato factual por excelencia de la leyenda Rimbaud. Por ello no es extraño que al final del libro el narrador sitúe al lector ("Vous, jeune homme de Douai ou de Confolens") junto a los devotos, sentado en una biblioteca hojeando el álbum en busca del significado de la obra, pues

le sens qui tourbillonne et s'en va dans les Iluminations, vous avez pensé avec quelque raison que vous le retrouveriez là, dans les très simples portraits d'hommes qui vécurent. [...] Vous avez vu ces hommes ; vous avez interrogé leurs portraits dans la petite iconographie canonique [...]. Page après page sous ces regards opaques vous vous êtes demandé ce que c'est qu'un témoin. Vous avez médité la vanité de ces portraits rassemblés là, et pourtant bien dévotement vous les avez interrogés (Michon, 1991: 98-99).

Los testigos ficticios con los que acaban siendo identificados el narrador y el narratario acaban meditando acerca de la vanidad de los testigos factuales (a quienes, en un claro giro metabiográfico, debe también recurrir el narrador biógrafo), testigos que, fosilizados por la iconografía, nada pueden aportar (la única actitud posible para aprehender a Rimbaud es la "devoción"). Por supuesto, la constatación final de fracaso es consecuencia del deseo mismo de intentar acceder a alguna verdad a través del archivo y la memoria cultural. En su defecto, lo que hace Michon es convertir las fotografías y reproducciones pictóricas del álbum (ausentes del libro, que no "domestica" sino que se nutre de todo el material documental subyacente, según una intertextualidad reconocida pero emancipada) en objeto de fantasía y motor de restitución alternativa de la escena que se supone que la fotografía o el cuadro debían inmortalizar. Jugando con la vulgata a través de procedimientos de invención y manipulación, el uso disfuncional del documento consiste básicamente en restituir una vida propia al documento mismo, que parece detener el esfuerzo

${ }^{11}$ El Album es referido en tres ocasiones. En la primera, se mencionan "les sels d'argent [...] reproduits à la page trente-neuf de l'iconographie rimbaldienne qui est ouverte sous mes yeux" (Michon, 1991: 41); en la segunda, la fotografía de Paul Demeny, "que les nitrates d'argent ont fixé lui aussi [...] à la page cinquante-quatre" (Michon, 1991: 61); y en la tercera, "la petite iconographie canonique [...], l'album Rimbaud en Pléiade" (Michon, 1991: 98). 
interpretativo previo, abocado al fracaso, para apropiárselo y hacer avanzar el relato a base de improbables narraciones, muy a menudo por medio de hipotiposis visionarias. Jean-Paul Goux (2004) ha inventariado en Rimbaud le fils una docena de esas escenas de hipotiposis, lo que representa casi un tercio de la obra. Cada una de ellas interviene en un momento crucial de la interpretación del "devenir Rimbaud", y por su función pueden ser de tres tipos diferentes: (1) repetición de una escena canónica de la vulgata para acusar su carácter estereotipado; (2) invención de una escena no conocida de la vulgata para sostener el propósito crítico, y (3) modificación de la interpretación canónica de un episodio de la vulgata. Sin embargo, incluso en esos osados episodios, a Michon le interesa más "decir" que "narrar", y utiliza con tanta discreción los marcadores de ficcionalidad que el texto se mantiene dentro de los límites del relato factual ${ }^{12}$. Es el caso, por poner un ejemplo, del episodio de la sesión de posado en el estudio de Carjat. El lector es invitado a seguir al grupo de poetas que, un atardecer de octubre, se presenta en casa del fotógrafo, en la rue Notre-Dame-de-Lorette. Faltan ciertas informaciones ("Nous ne connaissons pas leurs mots de 1871", Michon, 1991: 88), subsisten ciertas dudas ("On boit peut-être un verre", Michon, 1991: 88), el narrador especula a propósito de los pensamientos de Carjat ("Il se dit que tout à l'heure il faudra relever la cravate ; et puis que non, ce jeune homme est un poète, il est bon que la cravate des poètes penche", Michon, 1991: 89). Viene después un fragmento dedicado al instante en el que Carjat saca la fotografía, y en el que el narrador se permite el uso de la focalización interna en Rimbaud:

Carjat dit de bouger un peu la tête, comme ceci, puis comme cela. Il [Rimbaud] fait comme on lui dit, dans la tête qui bouge à peine les strophes impeccables, les strophes impassibles vers sur vers tombent, comme des vagues, comme du vent. [...] Il y a longtemps que Rimbaud ne respire plus. Carjat déclenche. La lumière se rue sur les halogénures, les brûle. Rimbaud à cet instant $r e-$ grette l'Europe (Michon, 1991: 91).

Pero en el párrafo siguiente, en un claro ejercicio de distanciamiento metaliterario, el narrador desautoriza la versión que acaba de dar de los hechos, neutralizando el procedimiento de la focalización interna que le habría permitido acceder a ellos: "Pas plus que nous ils [el grupo de poetas, testigos de la escena] ne savent sur quelle strophe Carjat a déclenché, quel mot il a mis en boîte ; non, nous ne savons pas si Rimbaud à cet instant regrettait l'Europe" (Michon, 1991: 92). Al poner al

\footnotetext{
${ }^{12}$ Utilizo la expresión "marcadores de ficcionalidad" en el sentido que le da Dorrit Cohn (1999), quien en el capítulo "Signposts of fictionality" de The Distinction of Fiction argumenta que lo característico de la ficción es el acceso a la interioridad de los personajes, sus pensamientos y sentimientos ocultos, eventualmente su flujo de conciencia: para el narrador de ficción no hay mentes opacas. Ivan Farron (2003) aborda el tema en las principales obras de Michon, que él sitúa en una "lógica de la duda" entre relato factual y relato ficcional propicia al desarrollo de la dimensión ensayística del texto. En todo caso, en Michon los dispositivos ficcionales sólo excepcionalmente conciernen al protagonista del relato.
} 
descubierto el hilo de las costuras del texto y exhibir el carácter dudoso de los episodios que propone, Michon parece jugar irónicamente con el género de la biografía novelada que, por ser "novelada", no se priva de las prerrogativas de la omnisciencia que son la marca de la ficción ${ }^{13}$.

Dos son, a mi entender, los sistemas explicativos de lo literario que Michon ridiculiza por su arbitrariedad y sus automatismos. El primero y quizás más evidente de estos sistemas es la historia de la literatura; y el segundo, la crítica y la teoría literarias (y no sólo las de orientación biográfica). La historia literaria no sería más que la idea de literatura convertida en un relato que avanza según la idea rudimentaria de sucesión. Este principio es seriamente problematizado por el "meteoro" Rimbaud, quien se niega a dejar ningún legado. Con su imagen de eterno adolescente, Rimbaud personifica, según Michon, al hijo por excelencia (un poco como Jesucristo). Se convierte hasta tal punto en el emblema de la figura del hijo que desactiva la noción de padre entendido como precursor, de modo que llegar a la literatura después de Rimbaud significa ser inscrito en la tradición únicamente como hijo. El autor es hijo de sus obras, no su padre. Y Rimbaud, al rechazar con su silencio final ser padre de sus escritos (y ya sabemos que el padre es la encarnación del Verbo), rompe con la supuesta transmisión dinástica de la literatura, transmisión que en Rimbaud le fils está parodiada por medio de la metáfora botánica del esqueje:

les jeunes [poètes] attendaient que les poètes en titre, c'est-à-dire ceux dont le nom avait au moins une fois dans un contexte frôlé le mot génie, que ceux-là donc leur accordassent un petit rayon de ce nimbe invisible qu'ils étaient réputés avoir sur la tête ; et qui se transmet comme par bouture, du plus vieux au plus jeune, mais que le jeune ne peut jamais voler tout à fait, fût-il Rimbaud ou saint Jean, il faut que le vieux donne (Michon, 1991: 37-38).

Esta mirada burlona sobre el fenómeno de la filiación literaria (trasunto, por otra parte, de la novela familiar tanto de Rimbaud como de Michon, hijos los dos de padres huidos, y que por tanto no se habrían podido posicionar como padres según el psicoanálisis) es menos inocente de lo que podría parecer a primera vista. A mi modo de ver, la idea de filiación imposible le sirve a Michon para desbaratar los conceptos de influencia y evolución en los que se basa en gran parte la historia de la literatura. Para Michon, la literatura no entiende de evolución ni de transformación, de procedencia o de dependencia, porque es siempre "reanudación" (recordemos la pregunta del éxplicit: "Qu'est-ce qui relance sans fin la littérature ?"). La reanudación es del orden del renacimiento o el resurgimiento, un nuevo comienzo o un nuevo impulso. No tiene que ver con una evolución o una transformación de las que pudiera atestiguarse en términos de avance, progreso o conquista. La reanudación,

${ }^{13}$ El error de adscribir la obra de Michon al género de la novela ha suscitado este comentario de Yves Reboul: "La critique allait vite conclure, de façon la plus moutonnière, qu'elle [la obra de Michon] relevait du genre narratif et réclamer de lui l'ouvrage au goût du jour, c'est-à-dire un véritable roman" (Bercot \& Guyaux, 1998: 753-754). 
en suma, no es del orden de la expansión, sino del orden de la pulsión (como el estilo mismo de Michon).

En cuanto al otro sistema explicativo de lo literario al que me refería más arriba (el de la crítica y la teoría de la literatura), Rimbaud le fils se convierte progresivamente en la vulgata de la teoría, cuyos conceptos clave - la obra, la poesía, la cualidad poética, el lenguaje, el sentido, etc. - son reexaminados a la luz de las diferentes escuelas críticas que se han aproximado a Rimbaud. Michon hace desfilar desde la psicobiografía hasta el estructuralismo, pasando por la sociocrítica y el psicoanálisis, sin olvidar el acercamiento místico, sea sagrado (Claudel) o profano (Breton). Pero la teoría, al convertir la literatura en objeto de reflexión y de conocimiento, es incapaz de explicar su enigma.

Esta mirada corrosiva e irreverente a la historia y la teoría literaria hace sospechar que para Michon la literatura como problema se ha deslizado de los ámbitos de la historia y la teoría al ámbito de lo existencial. Como apunta Ann Jefferson (2004), el formato de la biografía (tradicionalmente "no literario" o con poco prestigio, y subestimado por los estudiosos por ser poco dado a la experimentación) se ha convertido, paradójicamente, en el lugar en el que se plantea de nuevo la cuestión de la literatura. La literatura es algo que todo el mundo conoce pero que nadie puede nombrar. La literatura es un "acontecimiento": algo que ocurre, algo que se da, algo que se vive, pero de lo que no hay explicación suficiente, como si la única respuesta que pudiera suscitar fuese, simplemente, el hecho de escribir.

\section{REFERENCIAS BIBLIOGRÁFICAS}

Bercot, M. \& A. Guyaux (éd.), (1998) Dictionnaire des lettres françaises: le XX siècle. Paris, Librairie Générale Française.

Biasi, P.-M. de, (1990) "Les points stratégiques du texte" in Le Grand Atlas des littératures. Paris, Encyclopædia Universalis, pp. 26-27.

Boyer-Weinmann, M., (2005) La relation biographique: enjeux contemporains. Seyssel, Éditions Champ Vallon.

Cohn, D., (1999) "Signposts of Fictionality" in Cohn, D., The Distinction of Fiction. Baltimore/London, The Johns Hopkins University Press, pp. 109-131.

Derrida, J., (1980) "La Loi du genre/The Law of Genre" in Glyph. No 7, pp. 176201.

Dion, R., (2007) "Un discours perturbé: la fiction dans le biographique" in Dion, R. et al. (éd.), Vies en récit. Formes littéraires et médiatiques de la biographie et de l'autobiographie. Québec, Nota bene, pp. 279-299.

Farron, I., (2003) "La question des genres chez Pierre Michon" in Farron, I. \& K. Kürtös (éd.), Pierre Michon entre pinacothèque et bibliothèque. Berne, Peter Lang, pp. 123-139.

Gefen, A., (2012) "Au pluriel du singulier: la fiction biographique" in Critique. Vol. $6, n^{\circ} 781-782$, pp. 565-575.

Genette, G., (2003) "Fiction ou diction" in Poétique. No 134, pp. 131-139. 
Ghitti, J.-M., (2004) "Mort majuscule. Le mal et la vocation de l'écrivain" in Castiglione, A. (éd.), Pierre Michon. L'écriture absolue. Saint-Étienne, Publications de l'Université de Saint-Étienne, pp. 247-260.

Glaudes, P. \& J.-F. Louette, (1999) L'essai. Paris, Hachette.

Jefferson, A., (2004) "The Hagiographies of Pierre Michon: Rimbaud le fils" in French Studies. Vol. LVIII, no 2, pp. 205-217.

Goux, J.-P., (2004) "La scène fantasmée dans Rimbaud le fils" in Castiglione, A. (éd.), Pierre Michon. L'écriture absolue. Saint-Étienne, Publications de l'Université de Saint-Étienne, pp. 169-174.

Lacan, J., (1966) "Le stade du miroir comme formateur de la fonction du Je" in Écrits I. Paris, Seuil, pp. 89-97.

Langlet, I., (1995) Les théories de l'essai littéraire dans la seconde moitié du XXème siècle. Domaines francophone, germanophone et anglophone. Synthèses et enjeux. Rennes, Université de Rennes 2 - Haute-Bretagne.

Louis-Combet, C., (1995) Blesse, ronce noir. Paris, Corti.

Matarasso, H., \& P. Petitfils, (1967) Album Rimbaud. Paris, Gallimard, Coll. Bibliothèque de la Pléiade.

Macé, M., (2005) "Listes de genres: sur la place de l'essai dans l'imaginaire théorique" in La lecture littéraire. $\mathrm{N}^{\circ} 8$, pp. 125-139.

Michon, P., (1984) Vies minuscules. Paris, Gallimard, Coll. Folio.

Michon, P., (1991) Rimbaud le fils. Paris, Gallimard, Coll. Folio.

Michon, P., (1997) "Entretien avec Thierry Bayle" in Le Magazine littéraire. $\mathrm{N}^{\circ}$ 353, avril, pp. 97-103.

Michon, P., (2002) "Entretien avec Pierre-Marc de Biasi" in Le Magazine littéraire. $\mathrm{N}^{\mathrm{o}} 415$, décembre, pp. 96-103.

Richard, J.-P., (1993) "Pour lire Rimbaud le fils" in Bergounioux, P. et al. (éd.), Compagnies de Pierre Michon. Lagrasse, Verdier \& Orléans, Théodore Balmoral, pp. 117-140.

Ryan, M.-L., (2001) "Frontière de la fiction: digitale ou analogique ?" in Gefen, A. \& R. Audet (dir.), Frontières de la fiction. Québec, Éditions Nota bene, pp. 1741.

Vanoye, F., (1989) "La biographie, quand même" in Lejeune, Ph. (dir.), Le désir biographique. Nanterre, Université de Paris X, pp. 197-205.

Viart, D., (1999) Le roman français au XXe siècle. Paris, Hachette.

Viart, D., (2001a) "Dis-moi qui te hante. Paradoxes du biographique" in Revue des sciences humaines. $\mathrm{N}^{\mathrm{o}} 263$, pp. 7-33.

Viart, D., (2001b) "Essais-Fictions: les biographies (ré)inventées" in Dambre, M. \& M. Gosselin-Noat (dir.), L'éclatement des genres au XXe siècle. Paris, Presses de la Sorbonne Nouvelle, pp. 331-345.

Viart, D., (2002) "L'imagination biographique dans la littérature française des annéss 1980-1990" in Bishop, M. \& C. Elson (éd.), French Prose in 2000. Amsterdam/New York, Rodopi, pp. 15-34. 
Viart, D., (2003) "Les fictions critiques de Pierre Michon" in Castiglione, A. (éd.), Pierre Michon. L'écriture absolue. Saint-Étienne, Publications de l'Université de Saint-Étienne, pp. 203-219.

White, H., (1978) Tropics of Discourse: Essays in Cultural Criticism. Baltimore/London, The Johns Hopkins University Press. 